\title{
Additive Manufacturing of Titanium Alloys
}

\author{
M. QIAN $\oplus^{1,3}$ and D.L. BOURELL ${ }^{2,4}$ \\ 1.-Centre for Additive Manufacturing, School of Engineering, RMIT University, Melbourne, VIC 3000, \\ Australia. 2.-Mechanical Engineering and Materials Science and Engineering, University of Texas, \\ Austin, TX, USA. 3.—e-mail: ma.qian@rmit.edu.au. 4.—e-mail: dbourell@mail.utexas.edu
}

Titanium alloys are among the most extensively studied metallic materials in the broad context of metal additive manufacturing (AM), and the last decade has seen increased niche applications of additively manufactured titanium products. Additive manufacturing of titanium alloys continues to attract significant research attention today. Invited by the JOM editorial office, we have organized 13 solicited papers for the December 2017 issue of JOM under the topic "Additive Manufacturing of Titanium Alloys". The key features of each accepted contribution are summarized as follows.

In the first article titled "New Development in Selective Laser Melting of Ti-6Al-4 V: A Wider Processing Window for the Achievement of Fully Lamellar $\alpha+\beta$ Microstructures", Lui and co-workers investigated selective laser melting (SLM) of Ti$6 \mathrm{Al}-4 \mathrm{~V}$ alloy with the less commonly used layer thickness of $90 \mu \mathrm{m}$, with a view to broadening the flexibility of the SLM process. Fully lamellar $\alpha-\beta$ microstructures were produced in the as-built state through control of the interlayer time. As a result, the as-built Ti-6Al-4 $\mathrm{V}$ with a $90-\mu \mathrm{m}$ layer thickness achieved tensile ductility of $11 \%$ and a tensile yield strength of $980 \mathrm{MPa}$.

The second article, "Defect, Microstructure, and Mechanical Property of Ti-6Al-4 V Alloy Fabricated by High-Power Selective Laser Melting", by S. Cao et al. discusses the use of a high laser power $(350 \mathrm{~W}$, $800 \mathrm{~W}$, and $1000 \mathrm{~W}$ ) together with the accordingly adjusted parameters to improve the SLM productivity for Ti-6Al-4 V. The resultant microstructures and defects were characterized. Increasing laser power increased the build rate, but the formation of defects needs to be properly managed. Further systematic research appears necessary to fully identify and understand the influence of high laser power on the defect, microstructure, and mechanical property of SLM-fabricated Ti-6Al-4 V.

Ma Qian and David Bourell are the guest editors for the invited topic Additive Manufacturing of Titanium Alloys in this issue.
The third article by O. A. Quintana and W. Tong deals with the "Effects of Oxygen Content on Tensile and Fatigue Performance of Ti-6Al-4 V Manufactured by Selective Laser Melting". The oxygen content assessed was in the range of $0.110-0.164 \%$. As-built Ti-6Al-4 V samples containing $0.162 \% \mathrm{O}$ exhibited very high tensile strengths $(1360.9 \pm 5.5 \mathrm{MPa})$. After hot isotactic processing (HIP), samples containing $0.164 \% \mathrm{O}$ exhibited a fatigue strength of $645 \mathrm{MPa}$ compared with $595 \mathrm{MPa}$ for samples containing $0.118 \% \mathrm{O}$. The increase in oxygen content from $0.118 \%$ to $0.164 \%$ did not show a noticeable impact on the fatigue strength of notched specimens, which was in the range of $175-180 \mathrm{MPa}$.

In the fourth article, B. Torries and N. Shamsaei report on the "Fatigue Behavior and Modeling of Additively Manufactured Ti-6Al-4 V Including Interlayer Time Interval Effects". They investigated the influence of different cooling rates, as achieved by varying the interlayer time interval, on the fatigue behavior of Ti-6Al-4 V specimens fabricated via Laser Engineered Net Shaping (LENS ${ }^{\mathrm{TM}}$ ) and modeled the fatigue behavior using a calibrated microstructure sensitive fatigue (MSF) model. It was shown that the MSF model satisfactorily predicted the fatigue behavior of Ti-6Al-4 V specimens.

The fifth article by J. Gockel et al. focuses on the "Trends in Solidification Grain Size and Morphology for Additive Manufacturing of Ti-6Al-4 V". Using analytical, numerical, and experimental approaches, the authors provide a holistic view of the trends in the solidification grain structure of Ti$6 \mathrm{Al}-4 \mathrm{~V}$ across a wide range of AM process input variables. They concluded that within certain processing ranges, it is possible to indirectly control prior beta grain size through direct control of melt pool size.

The sixth article is concerned with how to manage powder bed fusion challenges including porosity, surface finish, distortions, and residual stresses of the as-built material. In this contribution, the authors present a "Numerical and Experimental 
Study of Ti6Al4 V Components Manufactured Using Powder Bed Fusion Additive Manufacturing”. Numerical optimization of SLM processing windows for Ti-6Al-V4 was performed using powder bed fusion process models validated with single track experiments. On this basis, SLM-fabricated Ti-6Al$4 \mathrm{~V}$ archived a relative density of up to $99.5 \%$. In addition, the numerical study conducted by the authors produced a range of insightful predictions of the SLM process.

In the seventh article, A. Macpherson and coworkers present a study on "Antibacterial Titanium Produced Using Selective Laser Melting" through elemental additions of $\mathrm{Cu}(5 \%)$ or $\mathrm{Ag}(0.5 \%)$ to prealloyed Ti-6Al-4 V powder. The Cu-containing SLM Ti-6Al-4 V showed moderate antibacterial properties and was superior to the Ag-containing alloy. An interesting finding was that an addition of $0.5 \% \mathrm{Ag}$ exerted no effect on the microstructure or strength but led to a $300 \%$ increase in the tensile ductility of the SLM Ti-6Al-4 V alloy.

In situ alloying represents a promising direction in metal AM. In the eighth article, I. Yadroitsev and co-workers report on "Titanium Alloys Manufactured by In situ Alloying During Laser Powder Bed Fusion". Powder mixtures of gas-atomized $\mathrm{CP} \mathrm{Ti}$ (Grade 2) powder with $15 \%$ Mo powder and gasatomized powder Ti-6Al-4 V ELI with $1.38 \% \mathrm{Cu}$ powder were prepared and additively manufactured using an EOSINT M280 system (EOS GmbH). The tensile strength of the in situ fabricated Ti-6Al-4 V$1.38 \mathrm{Cu}$ alloy reached $1550 \pm 126 \mathrm{MPa}$ with tensile elongation of $(4.53 \pm 1.60) \%$, compared with $1243 \pm 49 \mathrm{MPa}$ and $(6.6 \pm 0.4) \%$ without in situ alloying, respectively. The results demonstrated the feasibility of in situ alloying during laser powder bed fusion for titanium alloys.

In the ninth article titled "Microstructure and Mechanical Properties of Ti-6Al-4 V Fabricated by Selective Laser Melting of Produced by Granulation-Sintering-Deoxygenation (GSD) Method", P. Sun et al. present an informative assessment of a recent development made by the authors in the production of low-cost spherical Ti-6Al-4 V powder for AM through a granulation-sintering-deoxygenation (GSD) process. The tensile properties of the SLM Ti-6Al-4 V samples fabricated from the spherical GSD Ti-6Al-4 V powder are comparable with those of the mill-annealed Ti-6Al-4 V.

The tenth article by P. Wang et al. deals with an interesting case: "Study of Direct Fabrication of Ti6Al-4 V Impeller on a Wrought Ti-6Al-4 V Plate by Electron Beam Melting”. Based on detailed characterization of the defect, microstructure, and tensile properties, the authors concluded that the finished component, which was composed of a wrought base plate and an EBM-built section, was built in a satisfactory condition. The fusion zone was about $150 \mu \mathrm{m}$ thick, and no defect was observed along the fusion zone.

The eleventh article by B.A. Fisher investigates the "Consequences of Part Temperature Variability in Electron Beam Melting of Ti-6Al-4 V". As pointed out by the authors, "measuring temperatures is an important component of part quality monitoring in all direct metal AM processes". The temperature data were acquired through a custom thermal camera system attached to an Arcam EBM system to monitor surface temperatures. The solidification cooling rates determined from the temperature data were on the order of 50,000 K/s. Complicated temperature profiles were recorded after fusion of each layer. It was recommended that "a feedback control system for controlling solidification microstructure can be based on average surface temperature measurements, ignoring spatial variation in surface temperature".

The second-to-last article by J. Wang et al. focuses on characterizing the "Microstructure and Tensile Properties of Ti-48Al-2Cr-2Nb Rods Additively Manufactured by Selective Electron Beam Melting". The SEBM-fabricated Ti-48Al-2Cr-2Nb exhibited ultimate tensile strength of $603 \pm 18 \mathrm{MPa}$, yield strength of $555 \pm 11 \mathrm{MPa}$, and tensile elongation of $0.94 \pm 0.06 \%$ in the as-built state with a relative density of $99.8 \%$. The oxygen content changed from $0.089 \%$ in the powder to $0.093 \%$ in the as-built alloy (within the range of measurement errors), but the $\mathrm{Al}$ content decreased from $33.8 \%$ in the powder to $32.3 \%$ in the as-built alloy.

The last article is titled "Fabrication of Functionally-Graded $\mathrm{Ti}$ and $\gamma$-TiAl by Laser Metal Deposition". The authors employed a laser metal deposition (LMD) technique to join titanium aluminide alloy with commercially pure (CP) titanium through a gradient path fabricated with gas-atomized $\mathrm{CP} \mathrm{Ti}$ and Ti4822 powder blends. The microstructure and mechanical properties of the deposited material were characterized and compared with those of the as-cast material as reported in literature.

These articles are published under the topic "Additive Manufacturing of Titanium Alloys" in the December 2017 issue (vol. 69, no. 12) of JOM and can be accessed via the JOM page at http://link. springer.com/journal/11837/69/12/page/1. 